Memórias sobre as reflexões da (não) perenidade nos museus...

\title{
Memórias sobre as reflexões da (não) perenidade nos museus: a aquisição e a documentação nos Salões de Arte da Bahia
}

Anna Paula da Silva ${ }^{1}$

\section{Resumo:}

Este artigo apresenta algumas reflexões da dissertação defendida no mestrado do Programa de Pós-Graduação em Museologia da Universidade Federal da Bahia. O texto versa sobre questões da memória e do esquecimento nas narrativas das representações culturais, alguns (des)encontros durante a pesquisa, algumas das trajetórias investigativas e teóricas sobre a museologia, a aquisição e a documentação de obras de arte contemporâneas adquiridas nos Salões de Arte da Bahia, as questões sobre as obras efêmeras do Museu de Arte Moderna da Bahia, e a imaterialidade e a transitoriedade que problematizam a perenidade nos museus.

Palavras-chave: memória, documentação museológica, salões de arte da Bahia, Museu de Arte da Bahia, obras efêmeras.

\section{Abstract:}

This paper presented the thesis of museology master at Universidade Federal da Bahia. The text analyses questions of memory and oblivion in narratives of cultural representations, some encounters during in research, some investigative and theorical phases about museology, œuvres acquisition at Salões de Arte da Bahia and them documentation, the questions about œuvres ephemeral of Museu de Arte Moderna da

\footnotetext{
${ }^{1}$ Licenciada em História, bacharel em Museologia, mestre em Museologia, e atua como docente do curso de Museologia da Universidade Federal da Bahia.
} 
Bahia, and the intangible and transitory that rise the perenniality in museums.

Keywords: memory, museological documentation, salões de arte da Bahia, ephemeral œuvres.

\section{Introdução}

"Realmente, talvez chegue o dia em que os quadros e estátuas que hoje admiramos venham a ficar reduzidos a pó, ou que nos possa suceder uma raça de homens que venha a não mais compreender as obras de nossos poetas e pensadores, ou talvez até mesmo sobrevenha uma era geológica na qual cesse toda vida animada sobre a Terra; visto, contudo, que o valor de toda essa beleza e perfeição é determinado somente por sua significação para nossa própria vida emocional, não precisa sobreviver a nós, independendo, portanto, da duração absoluta" (FREUD, 1916).

No fragmento citado acima, Freud tem razão quando fala ao amigo que mesmo que as coisas deixem de existir, estas não deixam de ser belas e memoráveis. A nossa cultura ocidental tão fixa em noções de memória atribuídas a conjugação do tempo, tem o museu como um dos lugares que (re)constrói narrativas sobre memórias. Mas, mesmo esse museu com narrativas acerca da perenidade das memórias, encontra-se com questões sobre a transitoriedade de seus acervos.

Há quem divague sobre o museu como lugar de coisa velha, talvez até exista um senso comum sobre isto, ou mesmo, o museu como o lugar da eternidade, o lugar que as coisas vigoram sob o tempo e a sociedade, no entanto, esta divagação não se aplica ao que o leitor terá neste texto, afinal o museu representa o momento presente que dialoga com um passado longínquo e recente, e com as demandas representativas das coisas que preserva.

A discussão aqui é sobre a não perenidade nos museus, sobre a transitoriedade inerente a existência humana, sobre as coisas que mudam, se transformam, desaparecem, numa 
Memórias sobre as reflexões da (não) perenidade nos museus...

perspectiva do efêmero, adjetivo este utilizado neste texto como a apresentação das coisas como não perenes em suas dimensões tangíveis e intangíveis, que são ou não preservadas, fragmentos relacionados as representações de indivíduos e - ou - grupos sociais.

Este texto apresenta algumas das narrativas propostas na dissertação de mestrado defendida no Programa de Pós-Graduação em Museologia da Universidade Federal da Bahia (PPG Museu/UFBA), orientada pelo Professor Doutor Marcelo Nascimento Bernardo da Cunha, cujo título é Reflexões sobre a (não) perenidade nos museus: a documentação e a aquisição de obras nos salões de arte da Bahia.

Após um ano de dissertação defendida é possível estabelecer algumas outras relações sobre o objeto de estudo, no que tange a memória e o esquecimento. Na museologia, constituímos reflexões sobre paradigmas da necessidade preservacionista dos patrimônios presentes nas teorias, nos estudos de casos, que envolvem acervos, museus e suas práticas, entre outras pesquisas. Dentre esses autores, na pesquisa foi utilizado Pierre Nora (1981), e suas considerações sobre o lugar de memória, na intenção de afirmar o lugar do museu como o espaço de construção de significados sobre memórias fragmentadas e utilizadas em narrativas representativas de um indivíduo ou grupo social. $\mathrm{O}$ autor afirma que o lugar de memória tem como função "[...] parar o tempo, [...] bloquear o trabalho do esquecimento, fixar um estado de coisas, imortalizar a morte, materializar o imaterial". (Nora, 1981, p. 22) Será mesmo o museu um lugar do tempo estático e que bloqueia o esquecimento de memórias?

Há uma noção de coletividade desta memória e uma pretensa noção de preservação de coisas que são representativas, entendendo o museu como um templo das viagens no tempo, mas diante de outras leituras e análises sobre a noção de tempo para obras de arte efêmeras, a pesquisa tem se delineado de outras formas, principalmente, em relação as escolhas sobre as narrativas e o tempo, e o esquecimento. Nos últimos tempos, a leitura de 
Andreas Huyssen (2014) tem sido pertinente, pois agrega valor as noções de escolha nas narrativas, em seu primeiro parágrafo do texto Resistência à memória: usos e abusos do esquecimento público, o autor afirma:

Na cultura contemporânea, obcecada como é pela memória e o trauma, o esquecimento é sistematicamente malvisto. É descrito como uma falha da memória: clinicamente, como disfunção; socialmente, como distorção; academicamente, como uma forma de pecado original; em termos de vivência, como um subproduto lamentável do envelhecimento. Essa visão negativa do esquecimento, é claro, não é surpreendente nem particularmente nova. (p. 155).

Quando retomada a leitura da dissertação ocorre uma problematização desta visão negativa sobre o esquecimento, e que não existe a ausência do ato de esquecer na constituição de narrativas, pois se o museu é um lugar de seleção, quando enquadra as memórias automaticamente propõe exclusões, gerando esquecimentos. No texto em diante, Huyssen (2014) atribui a seleção - a escolha - de memórias, de narrativas e de discursos sobre momentos históricos, a exemplo do Holocausto e da ditadura na Argentina, à política de esquecimento público, onde toda construção se deu por uma memória hegemônica, mas que ao cabo também representa o esquecimento. A seleção de fatos e de como isso representa indivíduos e grupos é construída pelos paradigmas de quem seleciona e de como deve ser narrado: lembrar é também esquecer!

Neste sentido, este texto dialoga sobre a aquisição e a documentação de obras, que podem vir a ser narradas como memórias fragmentadas e escolhidas, e que por sua vez, são transitórias e demonstram a efemeridade de acervos de museus que estão em processo contínuo de desmaterialização, problematizando a noção de perenidade nos museus e seus discursos de eternidade sobre os acervos em dimensões tangíveis e intangíveis indissociavelmente. 
Memórias sobre as reflexões da (não) perenidade nos museus...

\section{Alguns (des)encontros}

Antes da escrita final da dissertação, os caminhos escolhidos levaram a encontros e desencontros, pois o objeto se transformava a cada tomada de decisão, seja por meio das orientações, de conversas com os pares, do mapeamento da documentação, das leituras e análises realizadas.

O tema da pesquisa do mestrado é documentação museológica, cuja presença se deu - e dá - em pesquisas passadas e no momento presente da autora desde a graduação em museologia, no que tange a produção teórica do campo do conhecimento da museologia e as interfaces com a documentação de obras de arte contemporânea. Nas produções, seja na dissertação, artigos e comunicações orais, ficou - fica - evidente a preocupação com obras sob as categorias efêmero e imaterial, tendo em vista a dificuldade de adquirir/ documentar/preservar obras transitórias e que tem em suas poéticas questões da materialidade perecível e da potência da imaterialidade inerente as coisas.

Inicialmente, o projeto de pesquisa apresentado ao Programa tinha como intuito a criação de uma linguagem padronizada (vocabulário controlado) para documentação de acervos institucionais que possuam obras contemporâneas, mas quando o campo aconteceu, a criação de um vocabulário controlado e a constituição de um sistema de recuperação da informação, cuja finalidade é a busca e o acesso as informações para a gestão de acervos, não era algo simples e apenas técnico, e só poderiam ser pensados a partir de pesquisas, ou seja, sobre os conhecimentos gerados dentro das instituições museológicas. Também era necessário reforçar o museu como um lugar de pesquisa por seus profissionais, e estabelecer reflexões sobre o papel do museólogo como um pesquisador que produz conhecimentos sobre os diferentes tipos de acervos.

Ao longo do mestrado, era reforçada a compreensão da 
documentação como uma prática de pesquisa, e o lugar que isto poderia ser evidenciado seria a partir do estudo da documentação museológica de alguma instituição. O professor Marcelo, orientador da pesquisa, sugeriu que o campo ocorresse no Museu de Arte Moderna da Bahia (MAM-BA), o que foi acatado pela autora.

A pesquisa de campo ocorreu a partir da pesquisa documental sobre como a documentação museológica é operacionalizada no MAM-BA, a partir das fichas de catalogação, a utilização da base de dados Donato, catálogos, projetos de artistas e pasta sobre as obras efêmeras. No mapeamento da documentação, houve um rompimento com a ideia de construção de um vocabulário controlado, pois a prática documental no museu apresenta questões sobre as dificuldades de classificação dos acervos, a duração de obras, questionando, então, a perenidade nos museus a partir de obras que demonstravam as possibilidades efêmeras e tornavam as imaterialidades pungentes em suas poéticas: é o caso dos prêmios aquisição dos Salões de Arte da Bahia, que para além de um evento que dimensionava obras de arte/mercado de arte/sistema da arte, constituía críticas e impulsionava reflexões sobre a história da arte, os salões também foram uma forma de aquisição de obras para o acervo do MAM-BA.

Entre os anos de 1994 a 2009, ocorreram 15 salões e foram adquiridas por meio dos prêmios aquisição 98 obras, com linguagens diversas: pintura, escultura, gravura, vídeo, vídeo instalação, fotografia, instalação, entre outras. A existência de algumas dessas obras se dá por meio dos vestígios documentais tanto do artista, com o envio dos projetos para os salões, quanto da produção de registros do museu seja por meio de fotografias, vídeos e os catálogos.

A delimitação mais elaborada do objeto de estudo surge a partir de dois encontros com os documentos relacionados aos salões: o primeiro com os projetos dos artistas que tiveram suas obras premiadas, cuja variedade de formatos chamava atenção, ainda que existisse um edital que norteava de forma objetiva como deveriam ser inscritas as obras; e o segundo com a pasta das três 
obras efêmeras, ao final do mestrado, e que de alguma forma representava as questões sobre a não perenidade nos museus, seja pelas dificuldades encontradas pela instituição em preservar determinados materiais e pela proposta transitória das obras, ou seja, questões sobre duração, assim como, a importância do registro na documentação museológica.

\section{Trajetórias da pesquisa}

A dissertação possui três seções: diálogos e narrativas da teoria e da documentação museológica; a (não) perenidade da obra de arte contemporânea no museu; e a documentação do MAM-BA: aquisição de obras nos Salões de Arte da Bahia. Essas seções criaram algumas trajetórias para o objeto de estudo, principalmente, a compreensão do campo do conhecimento da museologia e as relações com os museus, documentação museológica e a arte contemporânea.

Para a compreensão da museologia foram utilizados alguns teóricos e suas concepções sobre a teoria museológica, o estudo da cultura material e a musealidade. Nas acepções dos conceitos e das definições, a teoria museológica vai de encontro as práticas nos museus (Desvallées \& Mairesse, 2013, p. 63), a compreensão dos patrimônios, ou seja, as narrativas geradas das representações sobre esses patrimônios, a dinâmica da interdisciplinaridade nos diálogos com áreas afins e com as instituições (Bruno, 2006, p. 14), e sobretudo como enfatiza Mensch (1994), a museologia não é a ciência dos museus, mas "[...] todo museu tem que fazer uso dos princípios gerais da museologia". (p. 15).

Esses princípios gerais da museologia perpassam por teorizações das escolhas de perspectivas e narrativas sobre a memória e o esquecimento. $\mathrm{Na}$ pesquisa, optou-se por compreender o estudo da cultura material como uma possibilidade de análise das representações e das narrativas, sendo a materialidade e a imaterialidade a (re)construção da existência e da experiência humana. 
Por cultura material podera museologia perpassam por teorizaade de anescolhas de perspectivas e narrativa homem. Por apropriação social convém pressupor que o homem intervém, modela, dá, modela, dmaterial podera museologia perpassam por teorizaade de anescolhas de perspectio é aleatóleatdela, dmaterial podera museologia perpassam por teorizaade de anescolhas cluem os objetivos e projetos. Assim, o conceito pode tanto abranger artefatos, estruturas, modificações de paisagem, como coisas animadas (uma sebe, um animal doméstico) e, também, o próprio corpo, na medida em que ele é passíasstdela, dmaterial podera mo (deformações, mutilações, sinalaçõ, sinala dmaterial podera museologia perpassam por teorizaade de anescolhania litúrgica) (Meneses, 1985, p. 112).

Quando o conceito do autor citado acima foi apropriado para as discussões da pesquisa há uma ampliação conceitual, no sentido de dimensionar as discussões do estudo da cultura material não apenas para determinados objetos ou as suas funcionalidades, mas para as ações e a materialidade existente nas pessoas, a exemplo, do corpo, que mesmo na linguagem artística performance, cuja proposta é transitória no sentido de duração temporal, o corpo é um elemento material bem como os outros materiais utilizados pelo artista performer, mesmo sendo perecíveis, ou mesmo os registros como: livros de artistas, os vídeos e as fotografias. A matéria ainda que fragmentada representa a materialidade e a imaterialidade, as narrativas sobre as experiências e vivências.

O estudo da cultura material é constituída das nossas experiências existenciais na sociedade, pois despertam "[...] os nossos olhares, provocando novas interpretações e, em especial, sinalizando para a própria transitoriedade humana, desafiando a nossa capacidade de lembrar e os nossos compromissos com o esquecimento" (Bruno, 2009, p. 14).

Dentre outras discussões sobre o campo, a pesquisa também absorve as abordagens de Waldisa Rússio Guarnieri (2010, 
p. 180) sobre a museologia ser o estudo da relação sensível entre o homem, a realidade e os objetos nas dimensões material e imaterial, e o impulso dessa relação em ações transformadoras conforme o tempo vivido, é o que a autora intitula de fato museal; e o conceito de Ivo Maroevic (1997) sobre a musealidade como "[...] o valor imaterial ou a significação do objeto, que nos oferece a causa ou a razão de sua musealização". (p. 111)

As releituras possíveis dessas discussões levam a incorporação do estudo da cultura material a partir das dimensões tangíveis e intangíveis das memórias fragmentadas, pois são vestígios da existência humana, mesmo obras de arte contemporânea, que são legitimadas e enquadradas nos museus, sobretudo porque estabelecem uma relação entre arte e vida.

Neste sentido, na dissertação é afirmado o não consenso do que é museologia, mas ao reler o trabalho e frente as pesquisas realizadas atualmente, a abordagem criada para entender o objeto de estudo à época e os objetos de estudo no momento presente, é a compreensão da museologia como um campo de reflexões sobre as representações das memórias e dos esquecimentos, ou seja, das representações culturais em suas dimensões tangíveis e intangíveis, a partir das narrativas, que preveem seleção - presenças e ausências - e das ações dos indivíduos e dos grupos. Mas, qual é a relação entre teoria e a documentação museológica?

A documentação museológica é o que torna as representações culturais legíveis, pois é a partir dela que também são produzidos conhecimentos e que geram narrativas para outras pesquisas, para preservação e comunicação dessas representações. Dentre os referenciais apresentados na dissertação, o conceito chave da pesquisa e o mais explorado em outras pesquisas com a temática documentação museológica, é o de Helena Ferrez (1994). A autora entende a documentação como um conjunto de informações sobre os acervos e um sistema de recuperação da informação, cujo objetivo é transformar as "[...] informações em fontes de pesquisa ou em instrumentos de transmissão de conhecimento" (p. 64), e o outro autor utilizado é Gutiérrez Usillos 
(2010, p. 16), que evidencia a documentação no museu como um espaço de desenvolvimento da comunicação, um sistema de informação, que visa tornar acessível as informações para o público e para revalorização do patrimônio documental.

$\mathrm{Na}$ dissertação, há uma ampliação das abordagens dos autores acima citados, pois a documentação, além de um conjunto de informações, que desenvolve a comunicação e torna acessível as informações, é compreendida como processual e investigativa, por seu caráter de pesquisa e de preservação, tendo em vista a produção e o acesso ao conhecimento e, construída frente às necessidades preservacionistas da instituição.

Diante do que foi exposto sobre teoria e documentação museológica, insere-se a arte contemporânea, que por sua vez, é causa efeito, nesta pesquisa, para problematizar as abordagens teórico-práticas da museologia e as ações de instituições, no que tange, a ideia da perda e a noção de duração sob a preservação das representações culturais.

A arte contemporânea é uma arte que renova as formas de expressão artística existentes. Transgride limites desses diferentes meios de expressão artística, coloca-se entre eles, é 'intermídia' e transgride significados correntes no uso da cultura. Neste sentido, é uma arte que propõe um constante processo de 'resignificação'. É uma arte que põe em cheque a idéia de perenidade da obra, coloca em evidência a 'atitude', a situação em vez da forma (Gonçalves, 2005, p. 36).

As obras de arte contemporânea apresentam fronteiras sobre a noção preservacionista da memória, estas participam da lógica da musealização, pois são adquiridas, preservadas, pesquisadas, documentadas e comunicadas em instituições, mas como as noções de perenidade sob o respaldo da preservação podem salvaguardar a memória das obras de arte contemporânea?

Há formas de compreender e preservar os vestígios da produção humana, independente das categorias que os demarcam, as instituições lidam com diferentes tipos de acervos em um 
Memórias sobre as reflexões da (não) perenidade nos museus...

processo contínuo de compreensão do seu lugar de fala, das narrativas propostas, das transformações dos paradigmas da memória e do esquecimento, e com a arte contemporânea não é diferente, afinal as obras produzidas problematizam até a existência de museus e (re)significa as possibilidades da experiência com o mundo.

A compreensã compreensntínuo de compreensão do seu lugar aradigmas da memória e do esquecimento, e com a arte contemporânea não é diferente, afinal as obras produzidas probssos artísticos e seus suportes materiais eram incompatíveis com muitas das poéticas concebidas desde então. Buscava-se, em certo sentido, desfazer-se de algumas convenções que envolviam acordos institucionais. No Brasil, os artistas começaram a problematizar a homogeneidade do suporte, entendido por meio de sua essência material, no mesmo período. Além de Barrio - e antes dele -, Hé Hompreensnropostas, das transformações dos paradigmas da memória e do esquecimento, e com a arte contempocia Parente, Anna Bella Geiger tornaram-se nomes obrigatóia Parente, Anna Bella Geiger tornaram-se nomes obrigatda memória e do esquecimento, e com a arte contemporânea não é diferente, afinal as obras produzidas phappenings, às performances e às intervençõintervenes A(Oliveira, 2011, p. 2).

Neste sentido, a arte contemporânea problematiza e tem o seu lugar nas instituições, e o interesse desta pesquisa era - é compreender como seria possível analisar a densidade das propostas artísticas com diferentes linguagens e materiais, fundamentalmente, obras sob as categorias efêmero e imaterial: a primeira porque revela a transitoriedade proposta pelas poéticas dos artistas e pelos materiais utilizados; e a segunda, como uma categoria que parece mais evidente em obras de arte contemporânea, mas que está presente em todo e qualquer tipo de acervo, sendo a imaterialidade o elemento fundante e indissociável a materialidade para aquisição de objetos/ obras nos museus, como 
define Ivo Maroevic a partir da musealização conceituada como musealidade.

Desta forma, a pesquisa evidencia a importância da realização da documentação de obras de arte contemporânea a partir de registros fotográficos, audiovisuais, e quaisquer documentos que materializem os vestígios do que existiu, principalmente de obras efêmeras e - ou - obras que possuam em sua estrutura materiais perecíveis. É nesta perspectiva, que a dissertação possui um tópico sobre a desmaterialização processual e que rompe com a ideia do tempo inerte e da perenidade dos acervos de museus.

\section{A desmaterialização processual e o registro}

Mas o museu nio é s o museu nização processual e o registroncia da realizaação processual e o re obras de arte contemporânea a partir de registros fotográfinstánst da realizao sã st da realizaação processual e o re obras de arte conto volú vol (Millet, 1997, p. 77).

O museu legitima as memórias e os esquecimentos sobre narrativas das representações culturais, mesmo a arte contemporânea com a sua instabilidade é enquadrada pelo museu, pois este faz parte do sistema da arte, e constitui as suas narrativas sobre o passado e o presente de obras a partir da história e crítica da arte. A legimitação e o enquadramento são recortes, que se transformam com o tempo, que conjuga-se conforme as vontades e os anseios de indivíduos e grupos sociais, afinal o museu é um espaço que se resignifica e (re)cria sentidos. Dito isto, dentre as problematizações da arte contemporânea sob o museu, a pesquisa debruçou-se sobre a desmaterialização, que é atribuída as proposições de tempo das propostas artísticas aos museus no processo da (não) existência/da (não) perenidade.

A construção das análises sobre as possibilidades de desmaterialização surgiram das leituras do livro, Seis anos: a 
Memórias sobre as reflexões da (não) perenidade nos museus...

desmaterialização do objeto de arte de 1966 a 1972, de Lucy R. Lippard, e do livro, $A$ arte contemporânea: uma história concisa, de Michel Archer (2012), que versam sobre as propostas artísticas, as dificuldades de enquadramento e compreensão da produção artística a partir da década de 1960. Na dissertação, é apresentada a desmaterialização em três perspectivas:

[1a] obras que foram produzidas para um processo gradual de desmaterializacas, as dificuldades de enquadramento e compreensreensão da produção artística a partir da o é única temporalmente; [2um processo gradual de desmaterializacas, as dificuldades de enquadramento e compreensreensão da produção artística a partir da década de 1960. Na dissertação, é apresentada a desmaterialização em três perspec compõem; [3a] a desmaterialização como um processo resultante da perspectiva de vida rializacas, as dificuldades de enquadramento e compreensreensão nãnomo um processo resultante da perspectiva

Na primeira e na terceira perspectiva, a obra física deixa de existir, enquanto que na segunda, caso esteja registrado pela instituição e pelo artista, em comum acordo ou não, é possível que a obra seja (re)construída, criando também outras possibilidades de narrativas e análises sobre autoria. Fica evidente que a desmaterialização é processual independente do acervo, mesmo que o museu retarde com suas políticas de preservação a desmaterialização, isto não evita o desaparecimento da materialidade dos acervos. Portanto, como uma necessidade preservacionista, o registro é o que vigora como a possibilidade de que objetos - obras - em processo de desmaterialização e obras efêmeras sejam documentadas, sendo o registro um recorte e vestígio materializado daquilo que existiu. 


\section{O campo: Museu de Arte Moderna da Bahia}

O Museu de Arte Moderna da Bahia encontra-se na cidade de Salvador, sendo a sua sede no Solar do Unhão, conjunto colonial do século XVII, ao lado da Avenida Lafaiete Coutinho, conhecida como Avenida Contorno e com uma vista para Baía de Todos os Santos. Em 1959, o MAM-BA é criado, a partir do projeto de requalificação do espaço da arquiteta italiana Lina Bo Bardi (Gama, 2008 , p. 8). O museu é criado para ser um espaço de encontro das artes, e também pensado para desenvolver trabalhos com a arte popular, como sua idealizadora o tinha projetado. Com as transformações políticas e as necessidades de cada gestor, o MAMBA constitui diferentes modus operandi de trabalho nos diferentes tempos. É o que podemos perceber na análise dos catálogos, parte desta pesquisa foi construída a partir dessas publicações.

Para além dos catálogos, a pesquisa, como mencionado no início, foi constituída de um mapeamento da documentação museológica realizada pela equipe do Núcleo de Pesquisa e Museologia do pelo MAM-BA, mais especificamente.. O mapeamento traz, objetivamente, como a documentação é realizada, a começar pela aquisição que geralmente ocorre pelo diretor da instituição, e quando adquirida, a obra precisa estar atrelada a documentos dos artistas (projetos, dossiês, fotografias, etc), certificado de autenticidade, termos, laudos de conservação, registro em cartório, para que a procuradoria jurídica do órgão, a qual o MAM-BA é subordinado, a Diretoria de Museus do Estado da Bahia vinculado ao Instituto do Patrimônio Artístico e Cultural da Bahia, possa gerar um contrato a ser assinado e o número de tombo. Após, então, a formalização da aquisição, o MAM-BA realiza os registros sobre a obra.

O MAM-BA utilizou a base de dados Donato, no entanto, por um problema de servidor a base não é mais utilizada. É realizado o inventário, a instituição tem uma minuta das obras, os catálogos e algumas fichas antigas datadas das décadas 1980 e 1990 do século passado de obras adquiridas até a década de 1980 e 
já catalogadas e, estas fichas ainda são utilizadas. Mas, a instituição não possui uma política de aquisição e nem mesmo um projeto de documentação, ou seja, ocorre a catalogação, a pesquisa sobre o acervo, a constituição de laudos de conservação e outros registros, mas não existem documentos que formalizem o processo.

\section{Ângulos da pesquisa: a aquisição e a documentação de obras adquiridas nos Salões de Arte da Bahia}

A análise dos Salões de Arte da Bahia, por meio dos 15 catálogos e dos projetos dos artistas, caracterizou a pesquisa no sentido de compreender como o Salão repercute em ideias de seleção e exclusão, sendo uma instituição que contribui para outra instituição, que neste caso é o MAM-BA, na aquisição de obras para o acervo. Entre os anos de 1994 a 2008, o MAM-BA sediou os salões de arte, que em suas diferentes edições possuía duas comissões, a de seleção que escolhia os artistas participantes, eram apresentadas ao público de 30 a 40 obras; e a de prêmio-aquisição, que dentre as obras selecionadas algumas eram premiadas, entre 6 a 9 obras e, no total de 15 salões, foram adquiridas 98 obras para o acervo do MAM-BA.

Os dois diretores que geriram o museu durante esses Salões, Heitor Reis e Solange Farkas, nos textos escritos para os catálogos, enxergavam o evento como a renovação da instituição para visibilidade nacional e internacional e para o desenvolvimento do acervo, sendo crucial para o MAM-BA os prêmios-aquisição.

$\mathrm{Na}$ dissertação são apresentadas duas características que envolvem a aquisição por meio dos prêmios: "a primeira são as (in)definições da produção de arte contemporânea, que mesmo a teoria e história da arte [assim como a crítica] têm considerado complexas; a segunda, de que os critérios são variáveis e atestam uma necessidade de apresentar a diversidade da arte contemporânea" (Silva, 2015, p. 118-119).

Neste sentido, os salões viabilizam a aquisição de obras com diferentes linguagens, suportes, materiais e poéticas, mas ao 
mesmo tempo podem gerar complexidades nas ações do museu acerca da preservação e da documentação de obras, por isso a necessidade de que a equipe do museu, como museólogos, conservadores, restauradores e os demais profissionais participem dos salões, e que as abordagens específicas de cada área/ setor seja levada em consideração nas escolhas das comissões de premiação.

No mapeamento dos documentos respectivos a documentação museológica do MAM-BA, o encontro com os projetos de artistas de obras adquiridas pelos prêmios-aquisição dos Salões de Arte da Bahia foi o que norteou o objeto de estudo e deu base para compreender as relações de (não) perenidade e as categorias efêmero e imaterial. Os projetos representam os vestígios das obras, pois contêm desde a descrição da obra até o documento de montagem, e podem servir para compreender as concepções do artista, assim como, as escolhas da comissão de premiação.

A partir do que foi encontrado na pesquisa se constatou o quanto os projetos são heterogêneos por duas possibilidades, a primeira é a compreensão dos artistas sobre o edital do Salão e a segunda pela dificuldade de guarda dos documentos no museu, que por sua vez, pode não ter arquivado todos os documentos entregues pelos artistas. Ambas possibilidades eram o que se configuravam na pesquisa documental, afinal, alguns projetos continham a especificação completa de obras e outros apenas continham o passo a passo da montagem e - ou - a descrição dos materiais utilizados.

Atualmente, ao analisar a aquisição e a documentação das obras premiadas, a problemática se instaura conforme as possibilidades de narrativas sobre as obras adquiridas existentes, então, é complexo comunicar obras com tão poucos documentos para as curadorias e as publicações, e também existe a complexidade da relação conceitual e da missão da instituição entre os acervos oriundos de outros tipos de aquisição e as obras adquiridas nos salões.

Em relação as categorias utilizadas no desenvolvimento de 
Memórias sobre as reflexões da (não) perenidade nos museus...

reflexões para a pesquisa, a conservação e a comunicação nos museus daquelas obras: o imaterial pode ser analisado conforme os vestígios e os estudos da crítica e história da arte, da museologia e de áreas afins, que geram reflexões sobre a memória, a curadoria, a preservação e a exposição das obras, e a categoria efêmero, esta analisada, em duas perspectivas, a primeira pelo tempo de duração de exposição no salão das obras premiadas, que podem não ser mais expostas e guardadas durante anos nas reservas técnicas, e a segunda, obras que são transitórias por conta dos seus materiais e pela poética do artista, sendo a existência da obra marcada em um momento - tempo-espaço - específico do Salão e o que fica nos museus são os fragmentos e os vestígios do que existiu, é este o caso das obras efêmeras do MAM-BA.

\section{As obras efêmeras do MAM-BA}

No momento de escrita final e no meses próximos à defesa da dissertação, a equipe do Núcleo de Pesquisa e Museologia do MAM-BA apresenta à pesquisa a pasta de obras efêmeras, adquiridas no Salão de Arte da Bahia, são elas: "Organograma, de JoséJDasmaceno, do 4enSalão (1997); ${ }^{2}$ Sobressalto, de Maxim Malhado (2001), do 8)mSalão; Baíalo 8)m Malhadoscrita final e no meses de Eriel Araújo, do 10ArSalão (2003)" (2003)raalhados. 169).

A história contada sobre as obras efêmeras é que em 2010

\footnotetext{
2 "A obra de José Dasmaceno é um desenho, em que o artista utilizou hidrocor sobre papel. Na época, o artista fez esse desenho no espaço externo do MAMBA: 'Em sua série de Organogramas, Damasceno mapeia fluxos não-lineares do tempo por meio da ramificação das palavras ontem, amanhã e hoje'" [In: Disponível em:<http://www.fortesvilaca.com.br/artistas/jose-damasceno>. Acesso em: 14 ago 2015.] (Silva, 2015, p. 169).

3 "A obra de Maxim Malhado é uma construção em madeira (estroncas e ripões), com dimensão de $8 \mathrm{~m} \times 4 \mathrm{~m} \times 2 \mathrm{~m}$. Os pedaços em madeira foram fixados por pregos e construídos no espaço onde, antigamente, era a Capela" (Silva, 2015, p. 170).

4 "A obra de Eriel Araújo são fotografias submersas em água do mar, colocadas em pequenas caixas de vidro - uma instalação com dimensão de $10 \mathrm{~m}^{2}$ que estava fixada em uma parede no espaço expositivo" (Silva, 2015, p. 171).
} 
a equipe do museu se deu conta de que essas obras não foram adquiridas conforme previsto pela documentação museológica da instituição ou mesmo encontravam-se na reserva técnica. Para isso, a procuradoria jurídica do e outras instituições que possuíssem obras efêmeras em seus acervos foram contatadas, gerando assim um documento que formalizou essas obras como parte integrante do acervo do MAM-BA, evidentemente que não foi gerado um número de tombo, pois não existia mais matéria. $O$ documento define o que é obra efêmera: " procuradoria jurídica do e outras ina impermanê impermanoria jurídica do e outras instituições que possuíssem obras efêmeraria, breve"i(Núcleo de Museologia do MAM-BA, 2010). ${ }^{5}$

A incerteza de métodos de acolhimento, acondicionamento e registro de tais peças, implicaram na ocorrência de danos irreversíveis em algumas obras. Somado a isso, a vulnerabilidade da reserva técnica do MAM-BA, inadequada em termos espaciais, técnicos e tecnológicos, agravou e acelerou o processo de decomposição das peças constituídas por materiais altamente perecíveis e/ou baixa durabilidade (Núcleo de Museologia do MAM-BA, 2010)

Neste sentido, são duas constatações geradas a partir da análise desta pasta, a primeira é que o museu não tinha possibilidades de manter as obras em comunicação ou de conserválas por isso a instituição as definiu como efêmeras, e a segunda é que os artistas não as definiram como efêmeras. Mas, frente ao que foi analisado durante a pesquisa, a principal constatação é que todas as obras e os objetos de quaisquer museus estão sob as categorias imaterial e efêmero, pois a imaterialidade é inerente as obras e a transitoriedade faz parte da configuração da existência das coisas. Aparentemente, essas análises parecem óbvias, no entanto, ao fim e ao cabo ainda estamos sob um paradigma do museu da eternidade, e o estudo sobre a arte contemporânea faz

${ }^{5}$ Dossiê sobre as obras efêmeras encontra-se arquivado no MAM-BA. 
Memórias sobre as reflexões da (não) perenidade nos museus...

um convite à reflexão da não perenidade nas instituições.

\section{Consideraçõe Finais}

Esta dissertação pode gerar outras pesquisas sobre outras abordagens e possibilidades de análises, e ainda está em processo as análises sobre o campo do conhecimento da museologia, as questões sobre a transitoriedade nas instituições museológicas, a memória e o esquecimento como vetores para pensar as narrativas recortadas e selecionadas, e o caráter ficcional das memórias (re)significadas nos discursos preservacionistas.

A crítica de arte também se tornou um elemento para constituir reflexões e novas pesquisas sobre a recepção do público às obras de arte e o impacto das escolhas e narrativas das obras nos acervos institucionais e para a instituição de modo geral, tendo o catálogo como vetor dessas análises, pois é fonte de pesquisa, publicação de conhecimentos. Essas afirmações surgem, pois, uma boa parte da pesquisa do mestrado foi baseada nos três catálogos institucionais e nos 15 catálogos dos Salões de Arte da Bahia.

Por fim, a autora desenvolve projeto de extensão no MAMBA, afim de contribuir para requalificação do sistema de documentação museológica, que visa criar o projeto de documentação e tornar a gestão do acervo ainda mais eficiente tanto para os profissionais da instituição quanto para futuras pesquisas sobre o museu e suas práticas. Isto é posto diante da percepção da documentação como um processo de responsabilidade social e que configura possiblidades da diversidade de narrativas e (re)significação sobre as memórias construídas e preservadas no tempo presente. 


\section{Referências}

Archer, M. (2012).__Arte Contemporânea: uma histórica concisa. 2 ed. São Paulo : Editora WMF Martins Fontes.

Bruno, M. C. O. (2009). Estudos de cultura material e coleções museológicas: Avanços, retrocessos e desafios. In: M. Granato \& M. R. Rangel (Org.). Cultural material e patrimônio da ciência e tecnologia. (p. 14-25). Rio de Janeiro: Museu de Astronomia e ciências Afins.

Bruno, M. C. O. (2006). Museologia e museus: os inevitáveis caminhos entrelaçados. Cadernos de Sociomuseologia, 25. Disponível em: http://revistas.ulusofona.pt/index.php/cadernosociomuseologi a/article/view/419

Desvallées, A.; Mairesse, F. (2013). Conceitos-chave de museologia. São Paulo: ICOM-BR/ICOM/ Pinacoteca do Estado de São Paulo/ Secretaria de Estado da Cultura, 2013. Disponível em:< http://icom.museum/fileadmin/user_upload/pdf/Key_Concept s_of_Museology/Conceitos-ChavedeMuseologia_pt.pdf $>$.

Ferrez, H. D. (1994). Documentação museológica: teoria para uma boa prática. Estudos Museológicos. (p. 64-74). Rio de Janeiro: IPHAN.

Freud, S. (1916). Sobre a transitoriedade. In: S. Freud. Edição Standard Brasileira das Obras Psicológicas Completas de Sigmund Freud. Rio de Janeiro: Imago, 1996. v. XIV, p. 317.

Gama, M. (2008). O museu-escola de Lina Bo na Ribeira do Gabriel. In: O Museu de Arte Moderna da Bahia: catálogo. São Paulo: Banco Safra.

Gonçalves, L. R. (2005). Arte Contemporânea e Crítica de Arte. In L. R. Gonçalves \& A. Fabris (Org.). Os lugares da crítica de arte. (p. 35-46). São Paulo: ABCA: Imprensa Oficial do Estado,

Guarnieri, W. R. C. (2010). Museologia e Identidade. In: BRUNO, Maria Cristina Oliveira (Coord.). Waldisa Rússio Camargo Guarnieri: textos e contextos de uma trajetória profissional. Vol 1. São Paulo: ICOM/Governo de São Paulo/Pinacoteca do 
Memórias sobre as reflexões da (não) perenidade nos museus...

Estado de São Paulo, 2010.

Gutiérrez Usillos, A. (2010). Museologia y documentación: critérios para la definición de un proyecto de documentación en museos. Espanha: Ediciones Trea.

Huyssen, A. (2014). Resistência à memória: usos e abusos do esquecimento público. In: Huyssen, A. Culturas do passadopresente: modernismos, artes visuais, políticas da memória. (p. 155-176). Rio de Janeiro: Contraponto: Museu de Arte Moderna da Bahia.

Maroevic, I. (2006). O papel da musealidade na preservação da memória. In: Profa. Tereza Scheiner, disciplina Museologia 1. Rio de Janeiro: UNIRIO.

Meneses, U. T. B. (1985). A cultura material no estudo das sociedades antigas. Revista História. 115, 103-117.

Millet, C. (1997). A arte contemporânea. Lisboa: Flamarion.

Nora, P. (1981). Entre memória e história: a problemática dos lugares. Projeto História. Revista do Programa de Estudos PósGraduados em História e do Departamento de História da PUCSP (Pontifícia Universidade Católica de São Paulo). São Paulo.

Núcleo de Memória e Pesquisa do Museu de Arte Moderna da Bahia (MAM-BA). (2010). Relatório técnico para o IPAC: obras efêmeras. Salvador: Arquivo do Museu de Arte Moderna da Bahia.

Oliveira, E. D. G. de. (2011). Registros e ausências: arte contemporânea como desafio para historiadores da arte. In: 10을 Encontro Internacional de Arte e Tecnologia (\#.ART), Brasília.

Silva, A. P. da. (2015). Reflexões sobre a (não) perenidade nos museus: a documentação e a aquisição de obras nos Salões de Arte da Bahia. (Dissertação). Universidade Federal da Bahia, Salvador. 
Anna Paula da Silva 